\title{
SUMP SYNDROME: RELATO DE CASO
}

\author{
SUMP SYNDROME: CASE REPORT
}

\section{Ascêncio Garcia Lopes Junior,TCBC-PR ${ }^{1}$; Paulo Emílio Fuganti²; Sergio R. Spinosa ${ }^{3}$}

\section{INTRODUÇÃO}

A anastomose colédoco-duodenal é considerada tecnicamente fácil quando comparada as outras formas de derivação bílio-digestiva, proporciona uma boa drenagem da via biliar e é indicada para doenças benignas ou malignas da via biliar que levam à sua dilatação. No entanto, complicações como colangite ascendente, gastrite por refluxo alcalino e "sump syndrome" podem ocorrer ${ }^{1,2}$.

Esta operação é cada vez menos realizada devido aos avanços nos procedimentos endoscópicos que proporcionam resultados terapêuticos semelhantes a coledocoduodenostomia, mas com menor morbidade. Por esse motivo, a síndrome que relataremos a seguir é cada vez menos freqüente.

\section{RELATO DO CASO}

Um senhor de 53 anos, previamente hígido, foi submetido à colecistectomia e anastomose colédoco-duodenal látero-lateral em fevereiro de 2001, em outro serviço, por cálculos na vesícula biliar. Segundo a descrição da primeira operação não foram encontrados cálculos na via biliar, mas a drenagem do contraste para o duodeno estava comprometida e havia dilatação do colédoco na colangiografia intra-operatória. Por esses motivos optaram por uma anastomose bíliodigestiva colédoco-duodenal látero-lateral.

O paciente permaneceu assintomático por seis meses quando apareceram dores tipo cólica e/ou "peso", aguda em região mesogástrica com irradiação para as costas, principalmente após as refeições. As dores inicialmente eram pouco freqüentes e leves, mas foram progressivamente piorando. Em 2003 procurou atendimento médico e em março daquele ano fez uma CPER que observou a anastomose colédocoduodenal pérvea e normal, mas não avaliou o colédoco distal à anastomose e a papila/esfíncter de Odi. As dores pioraram, tornaram-se constantes, mas agravando-se às refeições; passou a fazer uso diário de paracetamol + fosfato de codeína e diclofenaco potássico. Passou a faltar ao trabalho com freqüência e emagreceu aproximadamente $10 \mathrm{Kg}$ ao longo de um ano. Não apresentou febre ou icterícia nesse período.
No início de 2004 , ainda em sua cidade natal, realizou uma TC de abdome que não mostrou alterações nas vias biliares ou pâncreas, tendo como única alteração cálculos renais. Foi submetido a uma avaliação com urologista que descartou a doença renal como origem da dor e o encaminhou ao nosso serviço. Avaliamos o paciente, solicitamos exames laboratoriais que mostraram apenas pequena alteração da fosfatase alcalina, uma nova CPER foi solicitada para avaliar toda a via biliar, a papila e também o ducto pancreático. A CPER mostrou anastomose ampla, via biliar normal proximal à anastomose (Figura 1), ducto pancreático normal (Figura 2) e falhas de enchimento no colédoco distal á anastomose, correspondendo a pequenos cálculos ou restos alimentares. Foi realizada a papilotomia endoscópica e a limpeza do colédoco distal com saída de resíduos alimentares.

O paciente evoluiu bem com alívio imediato dos sintomas, voltou a alimentar-se sem dor no dia seguinte ao procedimento endoscópico.

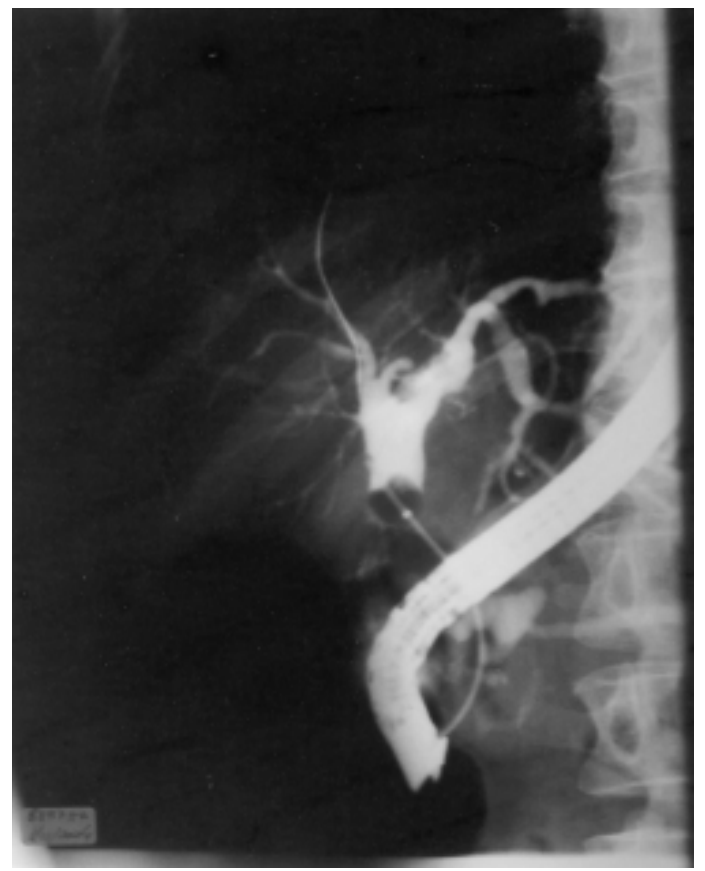

Figura 1 - Anastomose ampla e via biliar proximal normal.

1. Doutor em Cirurgia FMUSP; Cirurgião do Aparelho Digestivo - HU-UEL.

2. Doutor em Cirurgia FMUSP; Urologista da Santa Casa de Londrina.

3. Endoscopista do HU-UEL.

Recebido em 28/10/2005

Aceito para publicação em 28/12/2005

Conflito de interesses: nenhum

Fonte de financiamento: nenhuma

Trabalho Realizado no Hospital Universitário da Universidade Estadual de Londrina- PR. 


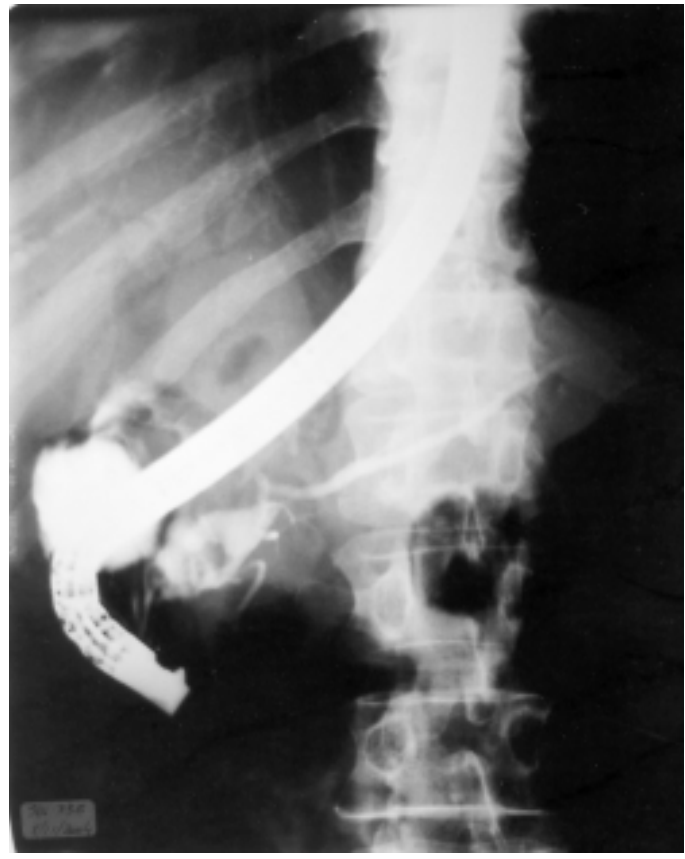

Figura 2 - Ducto pancreático normal.

\section{DISCUSSÃO}

A coledocoduodenostomia é realizada com menos frequiência atualmente, devido ao avanço dos procedimentos minimamente invasivos endoscópicos ou radiológicos que tratam boa parte das doenças benignas que acometem a via biliar e também proporcionam tratamento paliativo para um grande número de pacientes com doenças malignas. Por esse motivo, as complicações como colangite ascendente, abscesso hepático, gastrite por refluxo alcalino e "Sump Syndrome" são raramente observadas hoje em dia após anastomoses colédoco-duodenais ${ }^{1,3}$.

Em Londrina, as primeiras colangiopancreatografias endoscópicas retrógradas foram realizadas no início da década de 1980. Houve uma evolução grande nessa área e há vários anos procedimentos endoscópicos terapêuticos da via biliar são realizados de rotina na cidade, inclusive no HUUEL. Em decorrência disso, operações para descompressão da via biliar se tornaram menos freqüentes, incluindo as derivações colédoco-duodenais. $\mathrm{O}$ caso descrito foi a primeira "Sump Syndrome" observada no serviço de endoscopia do HU-UEL.
Acredita-se que o desenvolvimento da "Sump Syndrome" após uma anastomose colédoco-duodenal láterolateral ocorra devido à formação de pequenos cálculos e/ou ao acúmulo de material alimentar no colédoco distal à anastomose. A explicação para esse fato advém da estase biliar que ocorre no segmento do colédoco desfuncionalizado, proporcionando o aparecimento de cálculos e de infecção nesse local e também o acúmulo de restos alimentares ${ }^{2,3}$. Para que isso não ocorra é recomendado se fazer essa anastomose apenas quando o colédoco estiver dilatado (pelo menos 1,5 cm) e a anastomose tenha $2,5 \mathrm{~cm}$ de diâmetro ${ }^{1,2}$.

Os sintomas decorrentes da "Sump Syndrome" podem variar, mas normalmente ocorrem dor abdominal e febre, justificados plenamente pela fisiopatologia da doença. O tempo entre a cirurgia e o início dos sintomas também é variável, podendo ocorrer até vários anos após a coledocoduodenostomia, mas em média com tempo de latência de cinco anos ${ }^{4}$. Outro dado interessante é a demora em se chegar ao diagnóstico correto, Caroli-Bosc et al ${ }^{4}$ mostraram em seu trabalho que se leva seis anos em média entre a operação inicial e o diagnóstico; em nosso caso o tempo foi de três anos e o paciente passou por vários médicos nesse período. Esse dado reforça a importância de relatos de casos como esse.

O tratamento proposto para essa síndrome pode ser cirúrgico, principalmente nos casos onde há estenose da anastomose e debris densamente aderidos à parede do colédoco distal. O tratamento cirúrgico tem o objetivo de refazer a anastomose bílio-digestiva em Y-Roux, para evitar que os restos alimentares entrem na via biliar e retirar o colédoco distal do contato com a bile ${ }^{2}$. No entanto, hoje o tratamento de escolha é o endoscópico, como o realizado no nosso caso. O tratamento endoscópico, é um método seguro e eficaz, Caroli-Bosc et al trataram 30 casos de "Sump Syndrome" através da esfincterotomia endoscópica e não tiveram complicações ou recidiva dos sintomas ${ }^{4}$.

A "Sump Syndrome" cursa quase sempre com dor abdominal e este pode ser o único sintoma presente. Os exames laboratoriais podem ter alterações discretas e os exames de imagem podem ser normais. Portanto o diagnóstico clínico é difícil de ser feito e devemos sempre suspeitar dessa síndrome nos pacientes no pós-operatório de anastomoses colédocoduodenais. Em decorrência dos fatos expostos anteriormente a colangiopancreatografia endoscópica deve ser solicitada precocemente para se chegar ao diagnóstico e o tratamento através da papilotomia endoscópica deve ser a primeira escolha.

\begin{abstract}
Sump Syndrome after choledochoduodenostomy is becoming rare, mainly because endoscopic procedures are replacing this surgery. We report a case of this syndrome where the only symptom was pain. The diagnosis was made after 3 years and many doctors attended the patient. The treatment was endoscopic and the result was excellent (Rev. Col. Bras. Cir. 2007; 34(5): 354-356).
\end{abstract}

Key words: Postcholecystectomy Syndrome; Endoscopy; Postoperative Complications.

\title{
REFERÊNCIAS
}

1. Blumgart LH. Supraduodenal choledochotomy and choledochoduodenostomy: technique. In: Blumgart LH, Fong Y, editors. Surgery of the liver and biliary tract. $3^{\text {rd }}$ ed. Oxford: WB Saunders; 2000. p. 827-40. 
2. Jarnagin WR, Blumgart LH. Benign biliary strictures. In: Blumgart LH, Fong Y, editors. Surgery of the liver and biliary tract. $3^{\text {rd }}$ ed. Oxford: WB Saunders; 2000. p. 933-93.

3. Lachter J, Orron DE, Raskin GS. Choledochoduodenostomy. IMAJ. 2001;3(7):548.

4. Caroli-Bosc FX, Demarquay JF, Peten EP, Dumas R, Bourgeon A, Rampal P, Delmont JP. Endoscopic management of sump syndrome after choledochoduodenostomy: retrospective analysis of 30 cases. Gastrointest Endosc. 2000;51(2):180-3.
Como citar este artigo:

Lopes Jr A, Fuganti PE, Spinosa SR. Sump syndrome: relato de caso. Rev Col Bras Cir. [periódico na Internet] 2007 Set - Out; 34(5). Disponível em URL: www.scielo.br/rcbc

Endereço para correspondência:

Ascêncio Garcia Lopes Junior

Rua Cruzeiro do Sul, 350

Bairro Bela Suíça

86050-260 - Londrina - PR

E-mail: garcialopes@ sercomtel.com.br 